\title{
Impact of Therapy Persistence on Exacerbations and Resource Use in Patients Who Initiated COPD Therapy
}

This article was published in the following Dove Press journal: International Journal of Chronic Obstructive Pulmonary Disease

\author{
Faustine Dalon' \\ Gilles Devouassoux ${ }^{2,3}$ \\ Manon Belhassen ${ }^{1,4}$ \\ Gaëlle Nachbaur ${ }^{5}$ \\ Camille Correia Da Silva ${ }^{5}$ \\ Lynda Sail ${ }^{5}$ \\ Flore Jacoud' \\ Christos Chouaid (1D ${ }^{6}$ \\ Eric Van Ganse (iD) $1,2,4$ \\ 'PELyon, PharmacoEpidemiology, Lyon, \\ France; ${ }^{2}$ Pulmonary Department, Hôpital \\ de la Croix Rousse, Hospices Civils de \\ Lyon, Lyon, France; ${ }^{3} \mathrm{EA} 7426$, PI3, \\ Inflammation \& Immunité de L'épithélium \\ Respiratoire, Université Claude-Bernard- \\ Lyon I, Lyon, France; ${ }^{4}$ EA 7425 HESPER \\ Health Services and Performance \\ Research, Université Claude-Bernard- \\ Lyon I, Lyon, France; ${ }^{5} \mathrm{GlaxoSmithKline}$ \\ France, Pharmaco Epidemiology and \\ Health Economics and Outcomes \\ Research, Rueil-Malmaison, France; \\ ${ }^{6}$ Pulmonary Department, $\mathrm{CHI}$ de Créteil, \\ Créteil, France
}

Correspondence: Faustine Dalon PELyon, Immeuble Le Solaris, 210 Avenue Jean Jaurès, Lyon 69007, France Tel +33 48I 099605

Email faustine.dalon@pelyon.fr
Purpose: This study assessed therapy persistence in patients with chronic obstructive pulmonary disease (COPD) in France, and the impact of non-persistence on exacerbations and described COPD-related healthcare resource use (HRU).

Methods: Patients aged $\geq 45$ years who received $\geq 1$ dispensed bronchodilator per quarter over three consecutive quarters between 2007 and 2014 and initiated specific COPD therapy were selected from the Echantillon Généraliste des Bénéficiaires (EGB) database. Persistence, defined as the absence of dispensing gaps of $>90$ days, was measured at 12 months. Exacerbations were compared between persistent and non-persistent patients during follow-up after patient matching and adjustment for confounding factors. COPD-related HRU during follow-up was described.

Results: Among 4020 patients with COPD, 2164 initiated a specific therapy. Of these, $54.4 \%$ stopped treatment within 12 months. Persistence with all COPD therapy regimens was low, particularly for inhaled corticosteroid (ICS; 25.6\%) and ICS/twice-daily long-acting beta-agonist (39.4\%) regimens. Among 721 persistent patients who were matched with 721 non-persistent patients, there was no difference in the number of moderate or severe exacerbations at 12 months. However, medical procedures (for instance, pulmonary function testing and chest X-rays) were more frequently observed among persistent patients than among nonpersistent patients, suggesting worse disease severity.

Conclusion: Patients receiving specific treatment(s) for COPD demonstrated low persistence for all examined therapy regimens, with no clear impact of persistence status on the frequency of exacerbations at 12 months.

Keywords: COPD, therapy, persistence, exacerbations, healthcare resource use

\section{Introduction}

In individuals of 40 years of age and older, the prevalence of chronic obstructive pulmonary disease (COPD), as confirmed by spirometry, was estimated to be $7.5 \%$ in France in 2008, with an estimate of $4-26 \%$ in Europe, depending on the country. ${ }^{1,2}$ By 2030, COPD is projected to be the third leading cause of death worldwide. ${ }^{3}$ In France, COPD causes 18,000 deaths per year. ${ }^{4}$ Appropriate COPD management combining medications and non-pharmacological interventions enables symptom control, may slow disease progression, and improves patients' quality of life. ${ }^{5}$ The clinical management of COPD is based on well-established recommendations. ${ }^{6,7}$

Although effective COPD treatments are available, observational studies have shown varying results regarding the association of treatment adherence or 
persistence with exacerbations and healthcare resource use (HRU). ${ }^{8-12}$ While persistence is defined as the absence of critical gaps in treatment (ie continuation of therapy), adherence is defined as the regular intake of a drug (implementation). ${ }^{13-17} \mathrm{~A}$ good understanding of the level of COPD treatment persistence in patients could help optimize disease management and quality of care. The present study, conducted using a random sample of patients with probable COPD from the French general population who were covered by the national healthcare general scheme, was undertaken to: 1) describe COPD therapy persistence at 12 months in patients initiated on a specific COPD treatment, 2) evaluate the impact of nonpersistence on exacerbations, and 3 ) evaluate the impact of non-persistence on HRU.

\section{Methods}

\section{Study Design and Data Source}

This observational cohort study was conducted using the Echantillon Généraliste de Bénéficiaires (EGB) database. The EGB database contains a representative sample (1/ $97^{\text {th }}$ ) of the population covered by the French healthcare system (including approximately 66 million individuals), which records individual anonymous information from primary and secondary care institutions (data from the French Diagnosis Related Group-based medical information system [PMSI]), and currently covers more than $90 \%$ of the French population. ${ }^{18,19}$ The EGB database contains general characteristics (sex, year of birth, month and year of death where applicable, and free-access-to-care status [where $100 \%$ of healthcare expenses are covered for individuals whose financial resources are below a set threshold]), residence, long-term disease (LTD) status (full coverage for all medical expenses for patients registered with LTD status), all non-hospital reimbursed healthcare expenditures with dates and codes (visits, medical procedures, laboratory tests, drugs, and medical devices, but not the corresponding medical indications or results), and hospital discharge summaries (ICD-10 diagnosis codes for all medical, obstetric, and surgery hospitalizations with the date and duration of hospitalization, medical procedures, hospital department, and cost coding system).

This observational study was conducted using anonymized data and the CNIL (National Informatics and Liberty Committee) provided overall authorization for the use of the EGB data for research purposes. This study was conducted after approval by the French
Institute for Health Data (Institut des Données de Santé, approval $n^{\circ} 209$, September 21, 2016).

\section{Study Population}

Probable COPD was identified using proxies based on age ( $\geq 45$ years at inclusion) and bronchodilator treatment regimens: patients with at least one dispensed bronchodilator (including a twice-daily long-acting beta-agonist [LABA], once-daily LABA, inhaled corticosteroid [ICS]/twice-daily LABA fixed-dose combination [FDC], short-acting betaagonist [SABA], long-acting muscarinic antagonist [LAMA], short-acting muscarinic antagonist [SAMA], once-daily LABA/LAMA FDC and SABA/SAMA FDC) per quarter over three consecutive quarters between 2007 and 2014 were included, ie the "inclusion period" (Figure 1).

Patients who presented with asthma markers between 2006 and 2014 were excluded from the analysis. This included patients with an LTD status of asthma or patients hospitalized with a main, associated or related diagnosis of asthma (ICD-10 J45 and J46 codes), as well as patients who were dispensed antileukotrienes (ATC code R03DC03) or long-term oral corticosteroids (OCS) (10-20 mg/day, ie zeight dispensed units over a 12-month period). Patients who were dispensed fluticasone $50 \mu \mathrm{g}, 125 \mu \mathrm{g}$ or $250 \mu \mathrm{g}$, fluticasone DISKUS $100 \mu \mathrm{g}$ or $250 \mu \mathrm{g}$, or budesonide $100 \mu \mathrm{g}$ or $200 \mu \mathrm{g}$ (medication forms used in asthma) were also excluded.

The date of the first dispensing of a bronchodilator in the third quarter of the inclusion period was considered the inclusion date (Figure 1). To study persistence, a subgroup of patients who initiated a specific COPD therapy was identified, ie patients without any dispensed index treatment 12 months prior to the inclusion period. These patients had to have at least 15 months of follow-up (ie 12 months plus 90 days to assess persistence at 12 months). The index date was defined as the first dispensing of a specific COPD therapy (twice-daily LABA, oncedaily LABA, LAMA, twice-daily LABA/ICS, or oncedaily LABA/LAMA) after the end of the inclusion period.

The first 12-month period after the index date, termed the "exposure period", was used to assess therapy persistence status. The next 12-month period, termed the "follow-up period", was used to assess the impact of persistence on subsequent exacerbations and HRU (Figure 1). The population in which exacerbations and HRU were studied corresponded to a subgroup of patients, whose index date was between 2007 and 2013 and who 


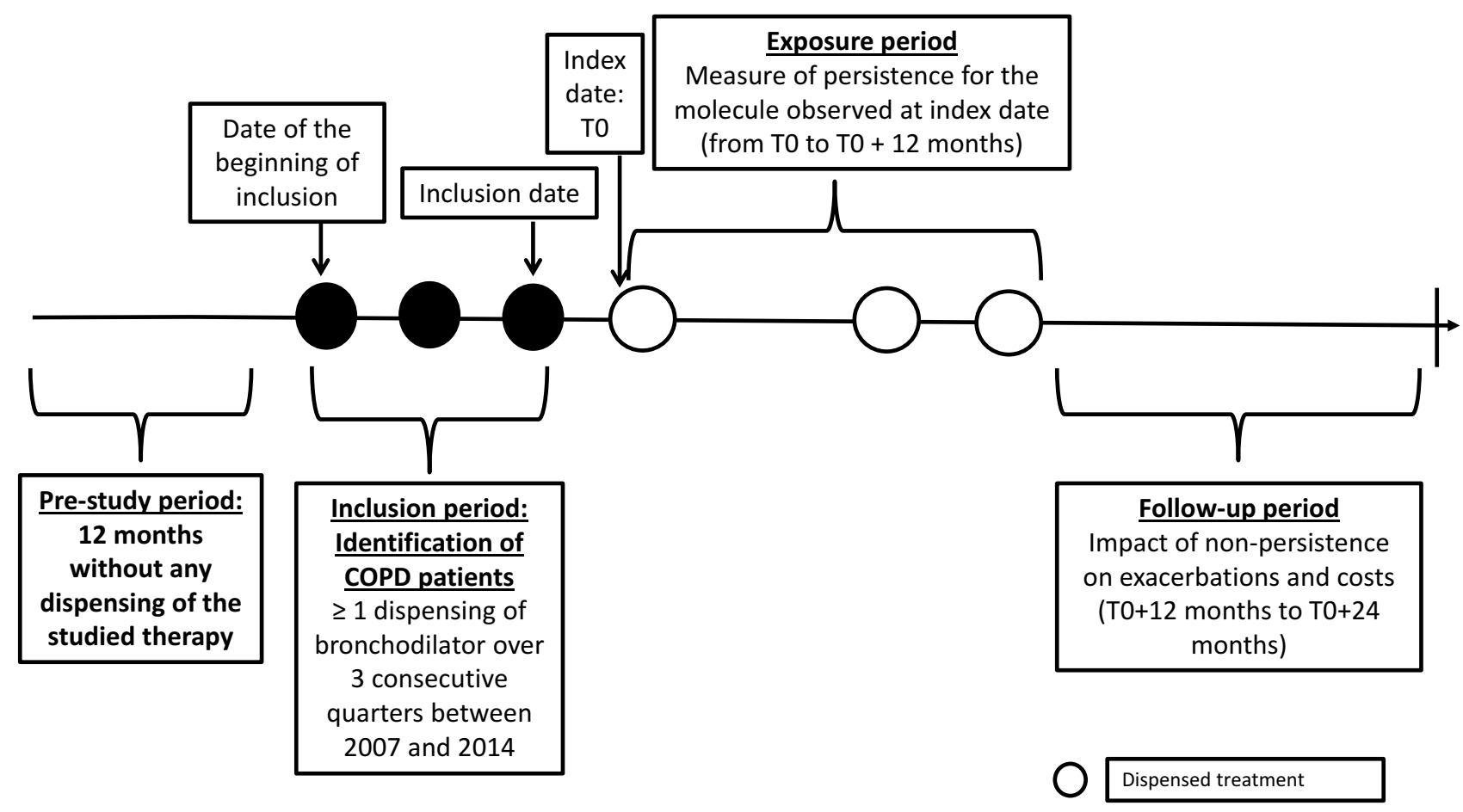

Figure I Study design.

had at least 24 months of follow-up available in the database.

Sociodemographic factors (age on the inclusion date, sex, and free-access-to-care status) were described at baseline, and clinical characteristics (presence of LTD status or hospitalization for COPD, comorbidities [identified by LTD or COPD-related hospitalizations], visits to primary care practitioners, visits to hospital practitioners and/or to respiratory physicians in private practice, number of COPD inhalers, use of oxygen therapy and/or noninvasive ventilation [NIV], and pulmonary function testing [PFT]) were examined over the exposure period.

\section{Outcomes}

\section{Treatment Persistence}

A patient was considered persistent if, during the exposure period, no treatment interruption exceeding 90 consecutive days was observed between the end of the coverage period and dispensing of the next prescription. This definition was based on the length of the coverage period of each treatment unit and the number of units: as one unit is usually prescribed for 30 days, 90 days corresponds to three times the usual duration of treatment use. A sensitivity analysis with 60 days as a gap cut-off instead of 90 days was conducted to assess the validity of the persistence definition.

\section{Exacerbations}

Exacerbations were classified as two levels of severity: moderate exacerbations were defined as a worsening of COPD symptoms requiring treatment with OCS (identified by ATC code H02AB, except injectable corticosteroids) and/or antibiotics (identified by ATC codes J01CA, J01CE，J01CF，J01CG，J01CR，J01DB，J01DC，J01DD, J01EE01, J01FA, J01FG and J01MA); and severe exacerbations were defined as those requiring hospitalization (identified by hospital discharge with a COPD diagnosis, based on ICD-10 codes J41, J42, J44, J96.1 and J96.0 when associated with $\mathrm{J} 43$ or J44). The number and type of exacerbations were evaluated during the follow-up period.

\section{COPD-Related Healthcare Resource Use (HRU)}

HRU was evaluated during the follow-up period. HRU included visits to general practitioners (GPs), respiratory physicians (private or hospital practitioners), and physiotherapists, medications (twice-daily LABA, once-daily LABA, ICS, LAMA, ICS/twice-daily LABA FDC, oncedaily LABA/LAMA FDC, SABA, SABA/SAMA FDC, SAMA, xanthines, oral and intramuscular corticosteroids, respiratory antibiotics, influenza and pneumococcal vaccines), PFT, X-rays and chest CT scans, NIV, oxygen therapy, nebulizers, all-cause hospitalizations, and hospitalizations for COPD. 


\section{Statistical Analysis}

\section{Patient Characteristics}

Sociodemographic factors and clinical characteristics (described above) were assessed using descriptive statistics, with means and standard deviations (SD) for continuous variables, and frequencies and percentages for categorical variables.

\section{Treatment Persistence}

Persistence with COPD treatment initiated on the index date was assessed over the 12-month exposure period using the Kaplan-Meier method. To obtain comparable groups, persistent patients were matched (1:1) to nonpersistent patients based on the following variables: age at index date \pm 5 years, sex, year of index date, and freeaccess-to-care status.

\section{Exacerbations}

To study the potential impact of non-persistence on exacerbations, the number of moderate and severe exacerbations was compared between matched groups of persistent and non-persistent patients over the 12-month follow-up period. To account for matching of data, the generalized estimating equation approach was chosen. A generalized linear model with a negative binomial distribution and log link function was used, adjusted for the following variables: the number of COPD inhalers, presence/absence of LTD or COPDrelated hospitalization, number of visits to a GP, occurrence of $\geq 1$ visits to a respiratory physician in private practice or to a hospital practitioner (regardless of specialty), presence/ absence of certain comorbidities (cardiovascular diseases, depression, cancer and diabetes), use or non-use of oxygen therapy, and use or non-use of NIV.

\section{Healthcare Resource Use}

HRU (number [\%] of users, and mean [SD] number of care events per user) was described separately for the persistent and non-persistent patients during the follow-up period.

All statistical analyses were performed with SAS version 9.4 (SAS Institute, Inc; Cary, NC).

\section{Results}

Of the 4020 patients with COPD identified in the EGB database after application of the selection algorithm, 2164 patients initiated COPD treatment after the inclusion date (Figure 2). Demographic and clinical characteristics for these patients are described in Table 1. Patients had a mean age of 66.0 years and most patients were male
$(60.0 \%)$. The most common comorbidity was cardiovascular disease (72.6\%).

Among the included patients, $2.3 \%$ were hospitalized at least once, with COPD as the main diagnosis, and 7.8\% had COPD LTD status, during the exposure period.

In the same period, $70.3 \%$ of the patients visited their GP more than four times, $36.7 \%$ had at least one contact with a respiratory physician or a hospital practitioner, and $28.7 \%$ underwent PFT. Also during this period, $30.8 \%$ of treatment-initiated patients used monotherapy (primarily LAMA [61.0\%]), 35.4\% received dual therapy (mainly ICS/twice-daily LABA [52.2\%]), and $23.2 \%$ received triple therapy (the most commonly used were ICS/twicedaily LABA/SABA [40.8\%] and ICS/twice-daily LABA/ LAMA [35.7\%]) (Table 2). In addition to their COPD treatment, $2.9 \%$ of the patients received NIV, and $2.5 \%$ received oxygen therapy (Table 1 ).

\section{Persistence at 12 Months}

Among the 2164 patients who initiated COPD treatment on the index date, 2489 treatment/patient pairs were identified (a patient could have initiated several treatments on the index date). Persistence at 12 months was $39.4 \%$ in those receiving ICS/twice-daily LABA, $25.6 \%$ in those receiving ICS, $46.1 \%$ in those receiving twice-daily LABA, $56.8 \%$ in those receiving LAMA and $57.0 \%$ in those receiving oncedaily LABA (Figure 3). The sensitivity analysis (gap of 60 days instead of 90 days) confirmed these trends; persistence was $30.1 \%$ in those receiving ICS/twice-daily LABA, $20.3 \%$ in those receiving ICS, $37.6 \%$ in those receiving twice-daily LABA, and $50.1 \%$ in those receiving LAMA or once-daily LABA (data not shown).

The Kaplan-Meier curves showed a significant decrease in persistence at 1 month and 2 months in those receiving ICS/twice-daily LABA, twice-daily LABA, and once-daily LABA, a significant decrease at 1 month and a smaller decrease at 2 months in those receiving LAMA, as well as a progressive decrease during the first 6 weeks, and a larger decrease at 2 months, in those receiving ICS (Figure 3).

According to the more restricted definition of persistence in the sensitivity analysis, patients exhibited less persistence with ICS/twice-daily LABA (the proportion of persistent patients decreased from $39.4 \%$ to $30.1 \%$ ) and twice-daily LABA (from $46.1 \%$ to $37.6 \%$ ) than with the other treatments studied. The smallest decrease in the proportion of persistent patients was observed with ICS (from $25.6 \%$ to $20.3 \%$ ) (data not shown). 


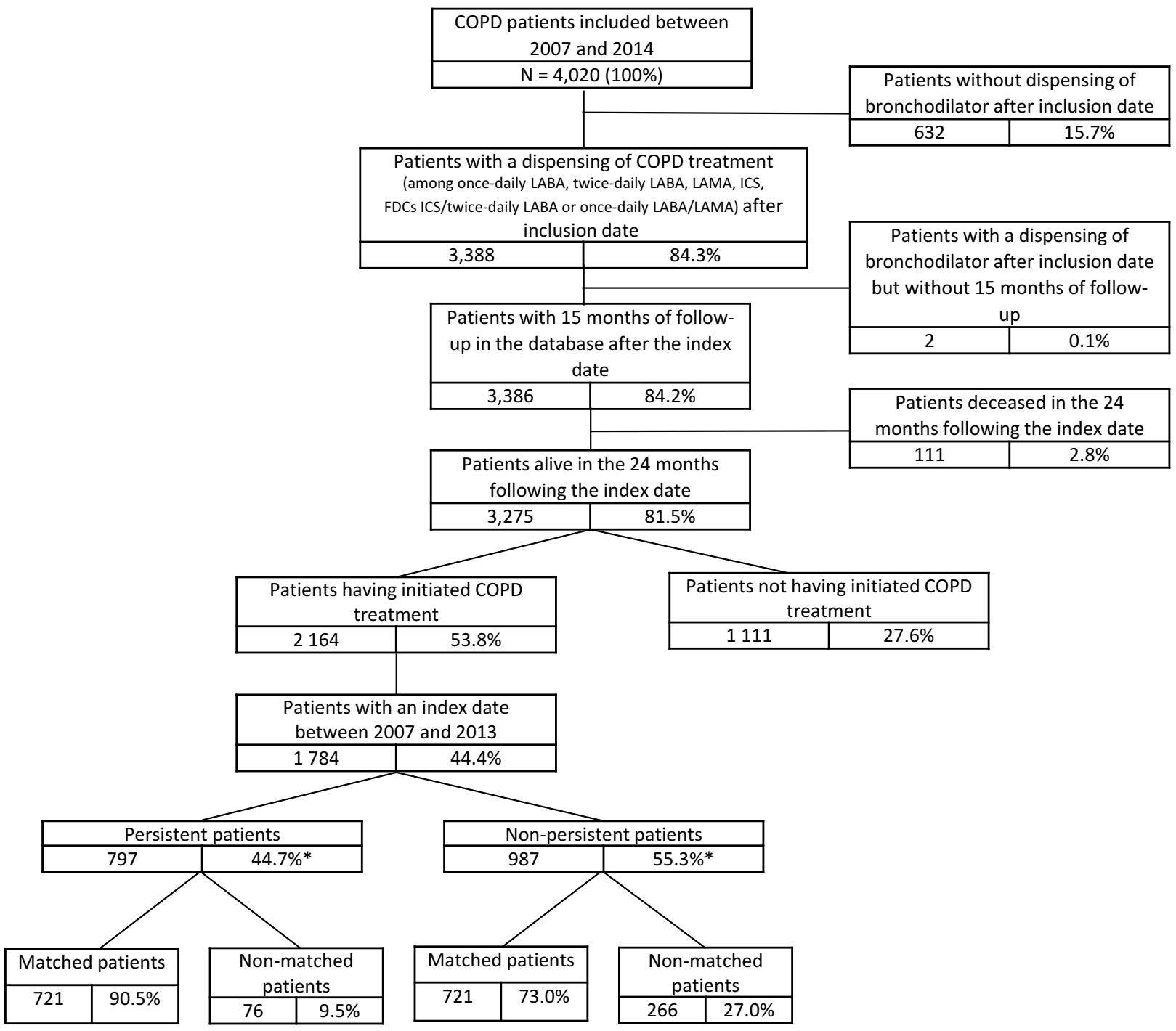

* Percentage based on the number of patients who initiated COPD therapy between 2007 and 2013

Figure 2 Flow chart.

The population in which exacerbations and HRU were studied corresponded to a subgroup of patients, whose index date was between 2007 and 2013 and who had at least 24 months of follow-up data available in the database $(\mathrm{N}=1784$, consisting of 797 persistent and 987 nonpersistent patients). To render the comparison as robust as possible, 1442 patients (721 comparable pairs of persistent/non-persistent patients) were matched (Figure 2).

\section{Exacerbations}

In the matched patients, there was no significant difference in the total number of exacerbations in the follow-up period according to persistence status. In total, $61.2 \%$ of persistent patients and $60.7 \%$ of non-persistent patients experienced an exacerbation $(\mathrm{p}=0.95) \quad$ (Table 3$)$. Irrespective of persistence status, the mean number of moderate exacerbations was 1.8 over 12 months in patients who experienced at least one exacerbation. The mean number of severe exacerbations was also similar between the two groups (Table 3).

\section{Healthcare Resource Use}

Overall, persistent patients used more COPD therapies than non-persistent patients. The mean number of dispensed units per patient was generally higher in persistent patients than in non-persistent patients (Table 4).

The mean number of visits to healthcare professionals was similar between persistent and non-persistent patients, 
Table I Characteristics of the Patients Who Initiated COPD Treatment During the Exposure Period ( $N=2164)$

\begin{tabular}{|c|c|}
\hline & $\begin{array}{l}\text { Patients } \\
N=2164\end{array}$ \\
\hline Age, years, mean (SD) & $66.0(11.4)$ \\
\hline Males, n (\%) & $1298(60.0)$ \\
\hline Free-access-to-care status, n (\%) & $110(5.1)$ \\
\hline $\begin{array}{l}\text { Long-term disease status* or hospitalization } \\
\text { for COPD, } n(\%) \\
\text { Hospitalization } \\
\text { LTD }\end{array}$ & $\begin{array}{l}202(9.3) \\
50(2.3) \\
169(7.8)\end{array}$ \\
\hline $\begin{array}{l}\text { Comorbidities, } \mathrm{n}(\%) \\
\text { Cardiovascular disease } \\
\text { Depression } \\
\text { Diabetes } \\
\text { Cancer }\end{array}$ & $\begin{array}{l}1572(72.6) \\
435(20.1) \\
397(18.3) \\
272(12.6)\end{array}$ \\
\hline $\begin{array}{l}\text { Visit to primary care practitioners, } n(\%) \\
0-4 \\
5-9 \\
10-14 \\
15-20 \\
20 \text { and over }\end{array}$ & $\begin{array}{l}642(29.7) \\
818(37.8) \\
425(19.6) \\
188(8.7) \\
91(4.2)\end{array}$ \\
\hline $\begin{array}{l}\text { Visit to physicians other than primary care } \\
\text { practitioners, } n(\%) \\
\text { At hospital (regardless of specialty) } \\
\text { Respiratory physician in private practice }\end{array}$ & $\begin{array}{l}794(36.7) \\
698(32.3) \\
166(7.7)\end{array}$ \\
\hline $\begin{array}{l}\text { Number of COPD inhalers, } n(\%) \\
\text { I } \\
2 \\
3 \\
4 \text { and over }\end{array}$ & $\begin{array}{l}971(44.9) \\
779(36.0) \\
285(13.2) \\
129(6.0)\end{array}$ \\
\hline Use of oxygen therapy, n (\%) & $54(2.5)$ \\
\hline Use of non-invasive ventilation, $n$ (\%) & $62(2.9)$ \\
\hline Pulmonary Function Testing, n (\%) & $622(28.7)$ \\
\hline
\end{tabular}

Notes: All $\mathrm{n}(\%)$ values indicate the number (percentage) of patients. *LTD: Patients registered with long-term disease benefit from full coverage for all medical expenses, with ICD-10 diagnosis codes, start and end date of LTD.

Abbreviations: COPD, chronic obstructive pulmonary disease; LTD, long-term disease; SD, standard deviation.

while most medical procedures, especially PFT and X-ray and CT scans, were used less frequently in non-persistent patients than in the persistent patients. Hospitalizations for COPD were similar in both groups (Table 4).

\section{Discussion}

Among the 2164 patients who initiated a specific COPD treatment, overall persistence was low. A majority $(54.4 \%)$
Table 2 Description of the COPD Therapies Dispensed During the Exposure Period $(\mathrm{N}=2164)$

\begin{tabular}{|l|l|l|}
\hline Treatment Combinations & Number & Percentage \\
\hline Monotherapy & 667 & 30.8 \\
ICS & 42 & 6.3 \\
Twice-daily LABA & 93 & 13.9 \\
LAMA & 407 & 61.0 \\
Once-daily LABA & 125 & 18.7 \\
\hline Dual therapy (two different & 767 & 35.4 \\
molecules)* & & \\
ICS/twice-daily LABA & 400 & 52.2 \\
ICS/LAMA & 37 & 4.8 \\
ICS/SABA & 116 & 15.1 \\
Twice-daily LABA/LAMA & 41 & 5.3 \\
Twice-daily LABA/SABA & 21 & 2.7 \\
LAMA/SABA & 46 & 6.0 \\
LAMA/once-daily LABA & 69 & 9.0 \\
All dual therapies represented in less & 37 & 4.8 \\
than I\% of the total number of patients & & \\
\hline Triple therapy* & 502 & 23.2 \\
ICS/twice-daily LABA/LAMA & 179 & 35.7 \\
ICS/twice-daily LABA/SABA & 205 & 40.8 \\
All triple therapies represented in less & 118 & 23.5 \\
than I\% of the total number of patients & & \\
\hline Other combinations* & 228 & 10.5 \\
ICS/twice-daily LABA/LAMA plus & 83 & 36.4 \\
SABA & & \\
All other combinations represented in & 145 & 63.6 \\
less than I\% of the total number of & & \\
patients & & \\
\hline
\end{tabular}

Note: *Only combinations in at least $2 \%$ of the total number of patients are detailed.

Abbreviations: ICS, inhaled corticosteroid; LABA, long-acting beta-agonist; LAMA, long-acting muscarinic antagonist; SABA, short-acting beta-agonist.

of patients had stopped therapy by 12 months, particularly those who received ICS or ICS/twice-daily LABA treatments, with discontinuation rates of $74.4 \%$ and $60.6 \%$, respectively. No impact of persistence status (persistent versus non-persistent) on exacerbation rates was observed, with $61.2 \%$ and $60.7 \%$ of matched persistent and nonpersistent patients, respectively, experiencing at least one exacerbation per year.

The overall study population of 4020 patients with COPD represents approximately $2 \%$ of the French population aged $\geq 45$ years with data available in the EGB between 2007 and 2014. Since the EGB includes approximately 660,000 people covered by the national health insurance scheme, the number of patients in France meeting the study criteria was estimated to be approximately 

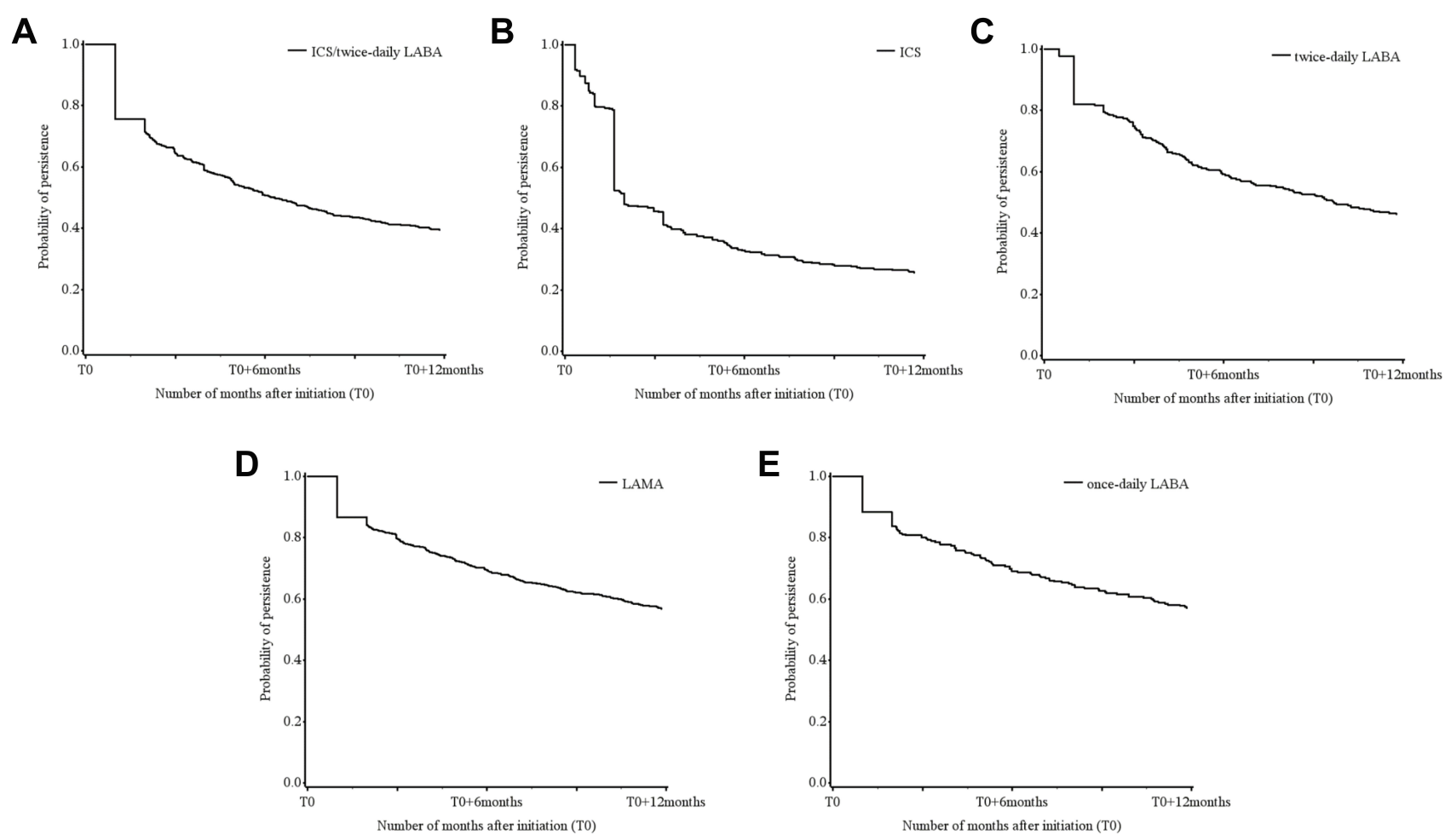

Figure 3 Persistence at 12 months to (A) ICS/twice-daily LABA ( $n=700)$, (B) ICS $(n=344)$, (C) twice-daily LABA ( $n=306)$, (D) LAMA ( $n=874)$, and (E) once-daily LABA $(n=265)$, using the Kaplan-Meier method.

$390,000 .{ }^{19}$ This figure must be contrasted with data on COPD prevalence $(7.5 \%)$ in the French population. This highlights the low number of patients with COPD who are diagnosed and treated, and the selectiveness of the algorithm that was used to identify this highly specific population. ${ }^{2}$ Indeed, this algorithm was intended to exclude asthma, or asthma-COPD overlap, as these patients might differ from "pure" COPD patients regarding their use of therapies. In this study, COPD severity seemed to be rather mild, as evidenced by the low proportion of patients with an LTD status, admitted to hospital, or requiring oxygen therapy or NIV.

The definition of persistence used in this study (noninterruption of treatment for 90 consecutive days) has been widely used for COPD. ${ }^{11,20-22}$ To support the validity of this definition, a sensitivity analysis was performed using a treatment discontinuation cut-off of 60 instead of 90 consecutive days; with a cut-off of 61 days, persistence was further decreased for each of the examined therapeutic classes. The persistence rates are consistent with those of a German study, which reported that $65.3 \%$ of patients were considered non-persistent at 12 months, ${ }^{14}$ and with other studies, irrespective of the method used to measure persistence. $^{12,23-25}$ This low persistence rate could in part be due to the moderate level of disease severity in this population; severity has previously been shown to impact therapy use in patients with COPD. ${ }^{26}$

No impact of persistence status on exacerbation rates was observed. However, previous studies have demonstrated varying results. ${ }^{10-12} \mathrm{~A}$ direct comparison is challenging as these studies used distinct methodologies: ${ }^{27}$ Antoniu et al demonstrated that high adherence to inhaled therapies reduced all-cause mortality and hospital admissions, but they performed a randomized trial in which patients' behavior was potentially influenced by the study design. ${ }^{10}$ A study by Simoni-Wastila et al in a Medicare population showed that COPD patients with higher adherence experienced fewer hospitalizations and lower costs than those with lower adherence. In their study, adherence was assessed by the proportions of days covered (PDC) and by persistence rates; however, the population assessed was not comparable to the population included in this study. ${ }^{11}$ Furthermore, unlike the United States, where Medicare gathers data from a targeted population, the EGB claims database contains data representative of the whole population since the French healthcare system is universal. In the review by van Boven et al, there was a clear association between non-adherence to COPD 
Table 3 Comparison of Exacerbation Numbers Between Persistent and Non-Persistent COPD Patients During the Follow-Up Period (Generalized Linear Model)

\begin{tabular}{|c|c|c|c|c|c|c|}
\hline \multirow[t]{2}{*}{ Exacerbations } & \multicolumn{2}{|l|}{ Persistent Patients ( $n=72 I)$} & \multicolumn{2}{|c|}{ Non-Persistent Patients $(n=721)$} & \multicolumn{2}{|c|}{$\begin{array}{l}\text { p-value: Persistent All* } \\
\text { vs Non-Persistent All* }\end{array}$} \\
\hline & $\begin{array}{l}\text { At Least One Exacerbation } \\
\text { Per Year }\end{array}$ & All* & $\begin{array}{l}\text { At Least One } \\
\text { Exacerbation Per Year }\end{array}$ & All* & $\begin{array}{l}\text { Non- } \\
\text { Adjusted }\end{array}$ & Adjusted** \\
\hline $\begin{array}{l}\text { All exacerbations } \\
\text { N (\%) } \\
\text { Mean (SD) } \\
\text { Median (IQR) } \\
\text { Min - Max }\end{array}$ & $\begin{array}{l}44 I(100) \\
1.8(1.1) \\
I(1-2) \\
I-6\end{array}$ & $\begin{array}{l}44 \mathrm{I}(6 \mid .2) \\
\mathrm{I} . \mathrm{I}(\mathrm{I} .2) \\
\mathrm{I}(0-2) \\
0-6\end{array}$ & $\begin{array}{l}438(100) \\
I .8(1.1) \\
I(I-2) \\
I-6\end{array}$ & $\begin{array}{l}438(60.7) \\
\text { I.I (I.2) } \\
\text { I }(0-2) \\
0-6\end{array}$ & 0.91 & 0.95 \\
\hline $\begin{array}{l}\text { Moderate } \\
\text { exacerbations } \\
N(\%) \\
\text { Mean (SD) } \\
\text { Median (IQR) } \\
\text { Min - Max }\end{array}$ & $\begin{array}{l}432(100) \\
1.8(1.1) \\
I(I-2) \\
I-6\end{array}$ & $\begin{array}{l}432(59.9) \\
\text { I.I (I.2) } \\
\text { I }(0-2) \\
0-6\end{array}$ & $\begin{array}{l}427(100) \\
I .8(1.1) \\
I(I-2) \\
I-6\end{array}$ & $\begin{array}{l}427(59.2) \\
\text { I.I (I.2) } \\
\text { I }(0-2) \\
0-6\end{array}$ & 0.86 & 0.93 \\
\hline $\begin{array}{l}\text { Severe } \\
\text { exacerbations } \\
N(\%) \\
\text { Mean (SD) } \\
\text { Median (IQR) } \\
\text { Min - Max }\end{array}$ & $\begin{array}{l}22(100) \\
1.2(0.7) \\
I(I-I) \\
I-4\end{array}$ & $\begin{array}{l}22(3.1) \\
0(0.2) \\
0(0-0) \\
0-4\end{array}$ & $\begin{array}{l}21(100) \\
1 . I(0.5) \\
I(I-1) \\
I-3\end{array}$ & $\begin{array}{l}21(2.9) \\
0(0.2) \\
0(0-0) \\
0-3\end{array}$ & $0.7 \mathrm{I}$ & - \\
\hline
\end{tabular}

Notes: *All: patients with or without exacerbation during the year. **Adjusted for the following confounding factors: number of COPD treatments, presence/absence of an LTD or COPD-related hospitalization, number of visits to a GP, occurrence of $\geq 1$ visit to a respiratory physician in private practice or to a hospital practitioner (regardless of specialty), presence/absence of comorbidities (cardiovascular diseases, depression, cancer and diabetes), use or non-use of oxygen therapy, use or non-use of NIV. Abbreviations: COPD, chronic obstructive pulmonary disease; GP, general practitioner; IQR, interquartile range; LTD, long-term disease; NIV, non-invasive ventilation; SD, standard deviation.

medication and poor clinical and economic outcomes. ${ }^{12}$ However, adherence was measured as PDC and persistence per se was not studied. Of note, ICS alone does not have marketing authorization for COPD in France; rather, it is only authorized as part of an FDC. Nevertheless, our data suggest the presence of inappropriate prescribing in a limited proportion of patients $(6.3 \%)$.

Matching was performed to evaluate the impact of nonpersistence on exacerbations, thus making persistent patients and non-persistent patients as comparable as possible. This method slightly decreased the size of the included study population ( $9 \%$ decrease from the sample of $n=2164)$. The number of patients $(n=76)$ lost to follow-up did not affect the statistical power of the results obtained.

In these patients, mild disease severity could explain the low number of observed exacerbations, and this low baseline incidence may potentially have masked an impact of persistence on exacerbation rates. However, an analysis using a model adjusted for known and available confounding factors was performed $(\mathrm{p}=0.95$ [95\% confidence interval: $0.90-1.12]$ ), which confirmed the initial finding of no significant difference in exacerbation rates between persistent and non-persistent patients. Our finding that persistent patients tended to undergo more intensive management of their condition than non-persistent patients (increased use of COPD treatments and an increased number of medical procedures) may have offset the fact that the severity of COPD in persistent patients was possibly increased. Indeed, the literature has shown that severe patients tend to exhibit increased persistence. ${ }^{28,29}$ Furthermore, available data (PFT, influenza and pneumococcal vaccines) suggest better management of care for persistent patients, possibly due to more frequent contacts with respiratory physicians.

\section{Limitations}

There are several limitations to this study. As is often encountered for database analyses, this study could not use validated medical diagnoses of COPD or clinical or technical results (such as spirometry data). Nevertheless, proxies, such as COPD therapy use over three consecutive quarters, were used to identify the condition, an approach that has been used in other COPD studies. ${ }^{30}$ The actual 
Table 4 Description of Healthcare Resource Utilization in Matched Persistent and Non-Persistent Patients During the Follow-Up Period

\begin{tabular}{|c|c|c|c|c|}
\hline & \multicolumn{2}{|c|}{ Persistent Patients $(n=72 I)$} & \multicolumn{2}{|c|}{ Non-Persistent Patients $(n=72 I)$} \\
\hline & $\begin{array}{l}\text { Number (\%) } \\
\text { of Users }\end{array}$ & $\begin{array}{l}\text { Mean (SD) Number of Care } \\
\text { Events Per User }\end{array}$ & $\begin{array}{l}\text { Number (\%) } \\
\text { of Users }\end{array}$ & $\begin{array}{l}\text { Mean (SD) Number of Care } \\
\text { Events Per User }\end{array}$ \\
\hline \multicolumn{5}{|l|}{ Visit to: } \\
\hline General practitioners & $695(96.4)$ & $8.3(6.1)$ & $676(93.8)$ & $8.1(6.0)$ \\
\hline Respiratory physicians & $47(6.5)$ & $1.7(1.2)$ & $31(4.3)$ & $2.1(2.9)$ \\
\hline Physiotherapists & $109(15.1)$ & $35.4(44.7)$ & $12 \mid(16.8)$ & $34.4(40.6)$ \\
\hline Hospital practitioners (all specialties) & $247(34.3)$ & $3.1(3.6)$ & $264(36.6)$ & $2.9(3.0)$ \\
\hline \multicolumn{5}{|l|}{ Medications } \\
\hline Twice-daily LABA & $|3|(\mid 8.2)$ & $8.9(4.1)$ & $70(9.7)$ & $5.5(4.4)$ \\
\hline Once-daily LABA & $130(\mid 8.0)$ & $9.2(4.2)$ & $5 \mathrm{I}(7.1)$ & $5.0(3.6)$ \\
\hline ICS & $138(19.1)$ & $7.7(8.4)$ & $104(14.4)$ & $3.3(3.5)$ \\
\hline LAMA & $419(58.1)$ & $9.4(3.8)$ & $160(22.2)$ & $5.4(3.8)$ \\
\hline ICS/twice-daily LABA FDC & $258(35.8)$ & $8.9(4.7)$ & $164(22.7)$ & $4.8(4.3)$ \\
\hline Once-daily LABA/LAMA FDC & $10(1.4)$ & $4.7(2.6)$ & $5(0.7)$ & $2.4(1.5)$ \\
\hline SABA & $174(24.8)$ & $6.0(6.8)$ & $182(25.2)$ & $4.6(5.3)$ \\
\hline SABA/SAMA FDC & $22(3.1)$ & I3.I (II.9) & $25(3.5)$ & $7.2(10.4)$ \\
\hline SAMA & $24(3.3)$ & $26.0(44.5)$ & II (I.5) & $22.0(29.1)$ \\
\hline Xanthines & $10(1.4)$ & I7.5 (II.0) & $8(1 . I)$ & $12.3(8.8)$ \\
\hline Oral corticosteroids & $183(25.4)$ & $1.7(1.4)$ & $182(25.2)$ & $\mathrm{I} .7(\mathrm{I} .2)$ \\
\hline Intramuscular corticosteroids & $44(6.1)$ & $3.0(2.4)$ & $59(8.2)$ & $2.8(3.5)$ \\
\hline Respiratory antibiotics & $408(56.6)$ & $5.1(4.7)$ & $4 I I(57.0)$ & $5.2(5.1)$ \\
\hline Influenza vaccine & $442(6 I .3)$ & I.0 (0.2) & $300(4 I .6)$ & $1.0(0.2)$ \\
\hline Pneumococcal vaccine & $50(6.9)$ & $1.0(0.1)$ & $28(3.9)$ & I.I (0.3) \\
\hline \multicolumn{5}{|l|}{$\begin{array}{l}\text { Medical procedures (in primary or } \\
\text { secondary care) }\end{array}$} \\
\hline Pulmonary Function Testing & $237(32.9)$ & $2.0(1.4)$ & $155(2 \mid .5)$ & $1.9(2.0)$ \\
\hline X-ray and chest CT scan & $277(38.4)$ & $2.1(2.8)$ & $227(31.5)$ & $2.0(2.4)$ \\
\hline Non-invasive ventilation & $31(4.3)$ & $39.2(22.3)$ & $15(2.1)$ & $37.8(22.3)$ \\
\hline Oxygen therapy & $17(2.4)$ & $34.7(22.0)$ & $24(3.3)$ & $38.4(19.5)$ \\
\hline Nebulizers & $53(7.4)$ & $5.0(5.5)$ & $39(5.4)$ & $3.8(4.4)$ \\
\hline \multicolumn{5}{|l|}{ Hospitalizations } \\
\hline All hospitalizations & $224(31.1)$ & $2.3(3.8)$ & $233(32.3)$ & $2.5(5.3)$ \\
\hline Hospitalizations for COPD & $22(3.1)$ & $\mathrm{I} .5(0.9)$ & $21(2.9)$ & I.4 (I.I) \\
\hline
\end{tabular}

Abbreviations: COPD, chronic obstructive pulmonary disease; CT, computed tomography; FDC, fixed-dose combination; ICS, inhaled corticosteroid; LABA, long-acting beta-agonist; LAMA, long-acting muscarinic antagonist; SABA, short-acting beta-agonist; SAMA, short-acting muscarinic antagonist; SD, standard deviation.

usage of medications also remains unknown: only dispensing data were used, without available information on the quality of inhaler device use or actual use by patients, and the observed non-persistence may thus be over- or underestimated. However, whereas other studies have typically used prescribing data, the claims data used in this study provided information on the actual dispensing of therapies by community pharmacies. This is a significant advantage as these data are closer to real medication consumption than prescribing data. It was also not possible in this study to assess whether patients or prescribers decided on treatment discontinuation, or the exact dates and reasons for discontinuation. Finally, and common to most if not all observational studies of COPD, residual confounding on COPD severity remains possible, although our careful matching and adjustment for severity mitigated this as far as possible.

\section{Conclusions}

This study demonstrated that COPD therapy persistence at one year was low for all treatment regimens. Some 
differences, such as decreased persistence with ICS/twicedaily LABA FDC and ICS alone, were observed. No impact of non-persistence on exacerbation rates was observed.

It will be of interest to repeat this study in a population of patients with severe disease, such as those hospitalized for COPD, where increased persistence rates could be expected. A qualitative study to investigate the possible causes of discontinuation (eg insufficient therapeutic response, adverse effects, or the complexity of use of the inhaler devices/dosage regimens) would also be of interest.

In summary, the findings of this study illustrate the need to improve the management of COPD and to identify new, more effective, therapeutic strategies. ${ }^{31}$

\section{Abbreviations}

COPD, chronic obstructive pulmonary disease; EGB, Echantillon Généraliste des Bénéficiaires; FDC, fixeddose combination; GP, general practitioner; HRU, healthcare resource use; ICD-10, International Classification of Diseases 10th Revision; ICS, inhaled corticosteroid; LABA, long-acting beta-agonist; LAMA, long-acting muscarinic antagonist; LTD, long-term disease; NIV, noninvasive ventilation; OCS, oral corticosteroids; PFT, pulmonary function testing; SABA, short-acting beta-agonist; SAMA, short-acting muscarinic antagonist.

\section{Acknowledgements}

We thank the French National Health Service (Caisse Nationale de l'Assurance Maladie) and the National Institute of Health Data (Institut national des Données de Santé) for providing the data. We also thank Gaëlle Le Moine for the coordination of the manuscript development.

This study was funded by GlaxoSmithKline plc. (study HO-16-17431).

\section{Disclosure}

GN, and LS are employees of GlaxoSmithKline (GSK) and own stock in GSK. CCDS was an employee of GSK at the time of the study. EVG is Scientific Advisor for PELyon and has had work sponsored by GSK, during the conduct of the study. FJ, FD, and MB (employees of PELyon) conducted the study through sponsorship by GSK and were not paid for manuscript development. CC reports personal fees from GSK, AZ, Novartis, during the conduct of the study. The authors report no other conflicts of interest in this work.

\section{References}

1. Blanco I, Diego I, Bueno P, et al. Geographical distribution of COPD prevalence in Europe, estimated by an inverse distance weighting interpolation technique. Int $J$ Chron Obstruct Pulmon Dis. 2018;13:57-67. doi:10.2147/COPD.S150853

2. Roche N, Dalmay F, Perez T, et al. Impact of chronic airflow obstruction in a working population. Eur Respir J. 2008;31 (6):1227-1233. doi:10.1183/09031936.00089607

3. Pelaia G, Muzzio CC, Vatrella A, Maselli R, Magnoni MS, Rizzi A. Pharmacological basis and scientific rationale underlying the targeted use of inhaled corticosteroid/long-acting beta2-adrenergic agonist combinations in chronic obstructive pulmonary disease treatment. Expert Opin Pharmacother. 2015;16(13):2009-2021. doi:10.1517/ 14656566.2015.1070826

4. INSERM. Bronchopneumopathie chronique obstructive (BPCO); 2014. Available from: http://www.inserm.fr/layout/set/print/thema tiques/sante-publique/dossiers-d-information/bronchopneumopathiechronique-obstructive-bpco. Accessed December 05, 2019.

5. Restrepo RD, Alvarez MT, Wittnebel LD, et al. Medication adherence issues in patients treated for COPD. Int $J$ Chron Obstruct Pulmon Dis. 2008;3(3):371-384. doi:10.2147/COPD.S3036

6. Vogelmeier CF, Criner GJ, Martinez FJ, et al. Global strategy for the diagnosis, management, and prevention of chronic obstructive lung disease 2017 report: GOLD executive summary. Eur Respir J. 2017;49(3):1700214. doi:10.1183/13993003.00214-2017

7. Wedzicha JA, Miravitlles M, Hurst JR, et al. Management of COPD exacerbations: a European Respiratory Society/American Thoracic Society guideline. Eur Respir J. 2017;49(3):1600791. doi:10.1183/ 13993003.00791-2016

8. Ismaila A, Corriveau D, Vaillancourt J, et al. Impact of adherence to treatment with tiotropium and fluticasone propionate/salmeterol in chronic obstructive pulmonary diseases patients. Curr Med Res Opin. 2014;30(7):1427-1436. doi:10.1185/03007995. 2014.908828

9. Alexopoulos EC, Malli F, Mitsiki E, Bania EG, Varounis C, Gourgoulianis KI. Frequency and risk factors of COPD exacerbations and hospitalizations: a nationwide study in Greece (Greek Obstructive Lung Disease Epidemiology and health ecoNomics: GOLDEN study). Int $J$ Chron Obstruct Pulmon Dis. 2015;10:2665-2674. doi:10.2147/COPD.S91392

10. Antoniu SA. Adherence to inhaled therapy in COPD: effects on survival and exacerbations. Expert Rev Pharmacoecon Outcomes Res. 2010;10(2):115-117. doi:10.1586/erp.10.10

11. Simoni-Wastila L, Wei YJ, Qian J, et al. Association of chronic obstructive pulmonary disease maintenance medication adherence with all-cause hospitalization and spending in a medicare population. Am J Geriatr Pharmacother. 2012;10(3):201-210. doi:10.1016/j.amjopharm.2012.04.002

12. van Boven JF, Chavannes NH, van der Molen $\mathrm{T}$, Rutten-van Molken MP, Postma MJ, Vegter S. Clinical and economic impact of non-adherence in COPD: a systematic review. Respir Med. 2014;108 (1):103-113. doi:10.1016/j.rmed.2013.08.044

13. Savaria F, Beauchesne MF, Forget A, Blais L. Adherence and persistence to long-acting anticholinergics treatment episodes in patients with chronic obstructive pulmonary disease. Ann Pharmacother. 2017;51(12):1063-1068. doi:10.1177/1060028017723349

14. Mueller S, Wilke T, Bechtel B, Punekar YS, Mitzner K, Virchow JC. Non-persistence and non-adherence to long-acting COPD medication therapy: a retrospective cohort study based on a large German claims dataset. Respir Med. 2017;122:1-11. doi:10.1016/j.rmed.2016.11.008

15. Bender BG. Nonadherence in chronic obstructive pulmonary disease patients: what do we know and what should we do next? Curr Opin Pulm Med. 2014;20(2):132-137. doi:10.1097/MCP.000000000000 0027 
16. Bereznicki BJ, Peterson GM, Jackson SL, et al. Describing drivers of and barriers to persistence with tiotropium in patients with chronic obstructive pulmonary disease: a mixed-methods approach. Int J Pharm Pract. 2015;23(2):154-157. doi:10.1111/ijpp.2015.23.issue-2

17. Bender BG, Hernandez Vecino RA, McGrath K, Jones S. Comparative analysis of persistence to treatment among patients with asthma or COPD receiving airflusal forspiro or seretide diskus salmeterol/fluticasone propionate combination therapy. J Allergy Clin Immunol Pract. 2016;4(5):884-889. doi:10.1016/j.jaip.2016.07.006

18. Martin-Latry K, Begaud B. Pharmacoepidemiological research using French reimbursement databases: yes we can! Pharmacoepidemiol Drug Saf. 2010;19(3):256-265. doi:10.1002/pds.1912

19. Tuppin P, Rudant J, Constantinou P, et al. Value of a national administrative database to guide public decisions: from the systeme national d'information interregimes de l'Assurance Maladie (SNIIRAM) to the systeme national des donnees de sante (SNDS) in France. Rev Epidemiol Sante Publique. 2017;65(Suppl 4):S149S167. doi:10.1016/j.respe.2017.05.004

20. Breekveldt-Postma NS, Koerselman J, Erkens JA, Lammers JW, Herings RM. Enhanced persistence with tiotropium compared with other respiratory drugs in COPD. Respir Med. 2007;101 (7):1398-1405. doi:10.1016/j.rmed.2007.01.025

21. Cramer JA, Bradley-Kennedy C, Scalera A. Treatment persistence and compliance with medications for chronic obstructive pulmonary disease. Can Respir J. 2007;14(1):25-29. doi:10.1155/2007/161652

22. Qian J, Simoni-Wastila L, Rattinger GB, et al. Association between depression and maintenance medication adherence among Medicare beneficiaries with chronic obstructive pulmonary disease. Int J Geriatr Psychiatry. 2014;29(1):49-57. doi:10.1002/gps.v29.1

23. Blackstock FC, Webster KE, McDonald CF, Hill CJ. Comparable improvements achieved in chronic obstructive pulmonary disease through pulmonary rehabilitation with and without a structured educational intervention: a randomized controlled trial. Respirology. 2014;19(2):193-202. doi:10.1111/resp.12203
24. Covvey JR, Mullen AB, Ryan M, et al. A comparison of medication adherence/persistence for asthma and chronic obstructive pulmonary disease in the United Kingdom. Int J Clin Pract. 2014;68 (10):1200-1208. doi:10.1111/ijcp.12451

25. Yu AP, Guerin A, Ponce de Leon D, et al. Therapy persistence and adherence in patients with chronic obstructive pulmonary disease: multiple versus single long-acting maintenance inhalers. J Med Econ 2011;14(4):486-496. doi:10.3111/13696998.2011.594123

26. Laforest L, Denis F, Van Ganse E, et al. Correlates of adherence to respiratory drugs in COPD patients. Prim Care Respir J. 2010;19 (2):148-154. doi:10.4104/pcrj.2010.00004

27. Vrijens B, Dima AL, Van Ganse E, et al. What we mean when we talk about adherence in respiratory medicine. $J$ Allergy Clin Immunol Pract. 2016;4(5):802-812. doi:10.1016/j.jaip.2016.05. 019

28. Laforest L, Belhassen M, Devouassoux G, Didier A, Ginoux M, Van Ganse E. Long-term inhaled corticosteroid adherence in asthma patients with short-term adherence. J Allergy Clin Immunol Pract. 2016;4(5):890-899.e2. doi:10.1016/j.jaip.2016.07.008

29. Vetrano DL, Bianchini E, Onder G, et al. Poor adherence to chronic obstructive pulmonary disease medications in primary care: role of age, disease burden and polypharmacy. Geriatr Gerontol Int. 2017;17 (12):2500-2506. doi:10.1111/ggi.2017.17.issue-12

30. Laforest L, Roche N, Devouassoux G, et al. Frequency of comorbidities in chronic obstructive pulmonary disease, and impact on all-cause mortality: a population-based cohort study. Respir Med. 2016;117:33-39. doi:10.1016/j.rmed.2016.05.019

31. van Boven JFM, Lavorini F, Dekhuijzen PNR, Blasi F, Price DB, Viegi G. Urging Europe to put non-adherence to inhaled respiratory medication higher on the policy agenda: a report from the first european congress on adherence to therapy. Eur Respir J. 2017;49 (5). doi:10.1183/13993003.00076-2017

\section{Publish your work in this journal}

The International Journal of COPD is an international, peer-reviewed journal of therapeutics and pharmacology focusing on concise rapid reporting of clinical studies and reviews in COPD. Special focus is given to the pathophysiological processes underlying the disease, intervention programs, patient focused education, and self managemen protocols. This journal is indexed on PubMed Central, MedLine and CAS. The manuscript management system is completely online and includes a very quick and fair peer-review system, which is all easy to use. Visit http://www.dovepress.com/testimonials.php to read real quotes from published authors. 